\title{
Dampak Keberadaan Penderita Gangguan Jiwa Terhadap Ketahanan Wilayah Kabupaten Jombang
}

Febiadi Faisal Hakim ${ }^{1}$

febiadifaisal@gmail.com

1 Prodi Ketahanan Nasional, Universitas Gadjah Mada, Yogyakarta

DOI: $10.22219 /$ sospol.v7i2.7460

\begin{abstract}
This study aims to explain the impact of the presence of people with mental disorders on regional resilience in Jombang Regency. The high number of people with mental disorders in the region has an impact on the threat of regional resilience which has the potential to disrupt existing social order. The implementation of this research uses qualitative research methods with an ethnographic approach. This research is a qualitative descriptive type, with an emphasis on 3 types of informants as research subjects, namely: people with mental disorders, knowing informants (family, community/religious leaders and social environment community) and expert informants (mental health specialists) through random sampling technique. The data collection technique used is through interview studies and documentation studies. As a result, the phenomenon of mental disorders in Jombang Regency has a negative impact on the resilience of the region, especially on (1) the economic aspect, namely the loss of self-productivity ability so that it has an impact on decreasing family economic resilience and low regional economic resilience, (2) social aspect, namely isolation. social distancing, the existence of shackles and the attachment of stigma and 'unstable' labeling on former people with mental disorders, (3) security forces, namely the emergence of terror due to the loss of public social order and the circulation of hoax news.
\end{abstract}

\begin{abstract}
Abstrak
Penelitian ini bertujuan menjelaskan dampak keberadaan penderita gangguan jiwa terhadap ketahanan wilayah di Kabupaten Jombang. Tingginya jumlah penderita gangguan jiwa di wilayah tersebut berdampak pada terancamnya ketahanan wilayah yang berpotensi dapat mengganggu ketertiban sosial yang ada. Pelaksanaan penelitian ini menggunakan metode penelitian kualitatif dengan pendekatan etnografi. Penelitian ini berjenis deskriptif kualitatif, dengan menitikberatkan pada 3 jenis informan sebagai subjek penelitian yakni: penderita gangguan jiwa, informan tahu (keluarga, tokoh masyarakat/agama dan masyarakat lingkungan sosial) dan informan ahli (dokter spesialis kesehatan jiwa) melalui teknik purposive sampling. Teknik pengumpulan data yang digunakan adalah melalui studi wawancara dan studi dokumentasi. Sebagai hasilnya, fenomena gangguan jiwa di Kabupaten Jombang memberikan dampak negatif terhadap ketahanan wilayah tersebut terutama pada (1) gatra ekonomi, yaitu hilangnya kemampuan produktivitas diri sehingga berdampak pada penurunan ketahanan ekonomi keluarga dan rendahnya ketahanan ekonomi wilayah, (2) gatra sosial, yaitu isolasi sosial, adanya tindakan pemasungan dan melekatnya stigma dan labelling gila pada mantan penderita gangguan jiwa, (3) gatra keamanan, yaitu munculnya teror akibat hilangnya ketertiban sosial masyarakat dan beredarnya berita hoax.
\end{abstract}

Keywords

Jombang, Ketahanan Wilayah, Ketertiban Sosial, Penderita

Gangguan Jiwa

\section{Article History}

Received January 16, 2019

Revised June 7, 2021

Accepted November 10, 2021

Published November 17, 2021

\section{Corresponding Author}

Febiadi Faisal Hakim. Prodi

Ketahanan Nasional,

Universitas Gadjah Mada, Jl.

Sosio Yusticia, Bulaksumur,

Yogyakarta. 55281. 


\section{Pendahuluan}

Kesehatan jiwa adalah salah satu elemen dasar untuk mewujudkan kemajuan bangsa. Gangguan jiwa menurut Ulmann termasuk dalam perilaku abnormal, jika seorang individu menunjukkan suatu tingkah laku yang berbeda, tidak mengikuti aturan yang berlaku, tidak pantas, mengganggu dan tidak dapat dimengerti dengan kriteria yang biasa maka tingkah laku tersebut dianggap abnormal baik yang berhubungan dengan fisik, maupun dengan mental (Slamet, Suprapti; Markam, 2007). Keabnormalan tersebut yaitu: gangguan jiwa (neurosa) dan sakit jiwa (psikosa). Berdasarkan data WHO pada tahun 2016 terdapat sekitar 35 juta jiwa penderita yang mengalami depresi, 60 juta jiwa mengalami gangguan bipolar, 21 juta jiwa mengalami Skizofrenia, dan 47,5 juta jiwa mengalami dimensia (Kemenkes RI, 2016). Bahkan dalam hasil Riset Kesehatan Dasar (Riskesdas) 2018 yang dilakukan oleh Kementrian Kesehatan mencatatkan terjadi peningkatan proporsi gangguan jiwa menjadi 7\%, artinya 7 dari 1000 orang penduduk di Indonesia mengalami gangguan jiwa berat. Angka tersebut lebih tinggi jika dibandingkan dengan hasil Riskesdas 2013 yang hanya $1,7 \%$ (Kemenkes RI, 2018).

Provinsi Jawa Timur sendiri memiliki jumlah orang dengan gangguan jiwa berat (ODGJ) non pasung sebanyak 40.312 orang dan orang dengan gangguan jiwa berat (ODGJ) sebanyak 3.579 orang (Kemenkes RI, 2018). Tingginya angka penderita gangguan jiwa berat dan pasung di wilayah Jawa Timur memaksa Gubernur Jawa Timur untuk merevisi program Jawa Timur bebas pasung dari tahun 2014 menjadi tahun 2019, dari jumlah tersebut sebanyak 2.071 jiwa berasal dari Kabupaten Jombang (Dinkes Kabupaten Jombang, 2020). Jumlah tersebut mengalami peningkatan dari tahun sebelumnya bahkan berdampak pada ketahanan wilayah di Kabupaten Jombang. Berangkat dari hal tersebut, penelitian ini berupaya menjelaskan dampak keberadaan penderita gangguan jiwa terhadap ketahanan wilayah di Kabupaten Jombang.

Pada aspek kesehatan, permasalahan kesehatan jiwa di Kabupaten Jombang perlu mendapatkan perhatian khusus. Jumlah ODGJ pada tahun 2015 hingga 2018 terus mengalami peningkatan, pada tahun 2015 sebanyak 1.086 jiwa masyarakat di Kabupaten Jombang menderita gangguan jiwa. Tahun 2016 jumlah penderita gangguan jiwa meningkat sebanyak 1.884 jiwa, tahun 2017 meningkat menjadi 2.343 jiwa dan hingga akhir 2018 jumlah penderita gangguan jiwa bertambah menjadi 2.701 jiwa. Jumlah ODGJ terbanyak berada pada wilayah kerja Puskesmas Perak dengan jumlah 187 penderita gangguan jiwa, keadaan tersebut berbanding terbalik dengan yang terjadi di wilayah kerja Puskesmas Bawangan yang memiliki 57 penderita gangguan jiwa namun terdapat 2 penderita gangguan jiwa yang dipasung.

Dalam kaitannya dengan relasi antara keberadaan penderita gangguan jiwa dengan ketahanan wilayah, terdapat riset terdahulu yang membahas mengenai hal tersebut. Seperti riset dari Lubis, Krisnani, dan Fedryansyah yang berfokus pada bagaimana pemahaman masyarakat terhadap adanya gangguan kiwa dan keterbelakangan mental (Lubis et al., 2014). Adapun riset dari Andina menyebutkan akan pentingnya perlindungan terhadap individu-individu yang mengalami gangguan jiwa (Andina, 2013). Benang merah yang menjadi kesamaan dari kedua riset tersebut ialah bagaimana di Indonesia sendiri pemahaman mengenai gangguan jiwa sangatlah minim, sehingga menyebabkan adanya mistreatment dari masyarakat yang berakibat pada adanya diskriminasi terhadap para penderita. Tentunya hal tersebut memperburuk kondisi dari para 
penderita, yang dapat berakibat pada tindakan-tindakan yang melanggar norma dan terganggunya ketertiban sosial. Penanganan yang tepat adalah dengan cara 'memanusiakan manusia', yakni dengan memberikan para penderita tersebut ruang untuk berkreasi sembari diimbangi dengan langkah meningkatkan kesadaran masyarakat tentang penderita serta penyakit tersebut agar dapat menciptakan masyarakat kolektif yang saling mendukung satu sama lain. Peran masyarakat seperti pemberian dukungan baik secara moril dan materil merupakan contoh upaya yang dapat meningkatkan kondisi sosial yang tangguh dan juga sebagai langkah kunci penyembuhan bagi para penderitanya (Lubis et al., 2014)

Melihat bahwa banyaknya ODGJ yang menerima perlakuan buruk dari masyarakat, upaya untuk melindungi kelompok tersebut serta pencegahan agar angka penderita tidak bertumbuh menjadi sebuah yang langkah krusial. Usaha tersebut menargetkan akarnya: yakni intensifikasi peran perlindungan masyarakat terhadap kelompok penderita gangguan jiwa tersebut, karena merekalah yang berinteraksi langsung dengan para penderita. Pada level birokrasi, pemerintah juga harus membuat peraturan yang dapat mencegah terjadinya kenaikan angka penderita dan memberlakukan prosedur penanganan yang konkrit terhadap para penderita. Sehingga masyarakat dan pemerintah perlu berkolaborasi untuk menciptakan kondisi lingkungan yang ramah bagi para penderita gangguan jiwa, sembari memperkuat perlindungan dari resiko penyakit tersebut baik secara preventif maupun rehabilitatif (Andina, 2013).

Tidak seperti dua penelitian diatas, yang hanya berfokus pada penderita gangguan jiwa dan bagaimana mereka mesti mendapatkan perlindungan, penelitian ini berupaya menjelaskan bagaimana dampak keberadaan penderita gangguan jiwa terhadap ketahanan wilayah di Kabupaten Jombang. Guna mempermudah bahasan, tulisan ini menggunakan konsep Gangguan Jiwa dan Ketahanan Wilayah. Menurut American Psychiatric Association (APA) gangguan jiwa adalah suatu syndrome atau pola psikologis atau perilaku penting secara klinis yang terjadi pada seseorang, dikaitkan dengan adanya distress atau disabilitas atau disertai peningkatan resiko kematian yang menyakitkan, nyeri, atau sangat kehilangan kebebasan (Videbeck, 2008). Sedangkan Moos mendefinisikan gangguan jiwa melalui pendekatan sosiokultural, menurutnya gangguan jiwa adalah manifestasi personal dari "penyakit" dan stres dalam masyarakat yang disebabkan karena adanya perubahan sosial, kemiskinan, diskriminasi dan tuna karya (Haas, 1997). Gangguan jiwa mewakili suatu keadaan tidak benar yang berhakikatkan penyimpangan dari suatu konsep normatif. Sehingga dalam penanganannya diperlukan tindakan-tindakan sosial untuk meningkatkan kesejahteraan sosial ekonomi dengan tujuan menciptakan masyarakat yang lebih adil dan sehat.

Sementara itu, konsep Ketahanan Wilayah merupakan bentuk mikro dari ketahanan nasional. Ketahanan wilayah bersifat dinamis, bergerak mengikuti perkembangan suatu daerah sehingga ketahanan wilayah harus dikembangkan dan dibina agar dapat bertahan dan mengikuti dengan perkembangan. Ketahanan wilayah yang baik akan memberikan dampak positif terhadap stabilitas keamanan dan pembangunan di suatu daerah, begitupun sebaliknya fenomena yang terjadi pada suatu daerah dapat memberikan pengaruh terhadap ketahanan wilayah. Terdapat tiga pengertian yang melekat pada ketahanan wilayah, yaitu menerangkan tentang fenomena, pedoman untuk bertindak dan integrasi dari berbagai kondisi kehidupan masyarakat yang dapat dinilai dengan memilih jenis parameter yang akan diukur (Amal, 1995). Ketertiban sosial juga menjadi 
salah satu indikator dalam ketahanan wilayah yang termasuk dalam gatra sosial budaya dan gatra pertahanan keamanan di wilayah tersebut.

Ketangguhan ketahanan wilayah dapat dipengaruhi oleh perkembangan fenomena sosial di masyarakat dan upayanya dalam mengatasi permasalahan yang ada, semakin cepat kemampuan suatu daerah dalam mengatasi permasalahan maka semakin kuat juga ketahanan wilayahnya, begitu pun sebaliknya. Ketahanan wilayah sendiri merupakan suatu kondisi dinamik masyarakat dalam suatu wilayah, meliputi segala aspek kehidupannya secara terpadu yang terdiri dari keuletan dan ketangguhan masyarakat dalam menangkal segala ancaman, tantangan, hambatan dan gangguan baik langsung maupun tidak langsung untuk menjamin identitas, integritas kelangsungan hidup dalam mengembangkan seluruh potensi dan kekuatan yang dimiliki agar terwujud ketahanan wilayah yang tangguh dengan astagatra yang terdiri dari trigatra dan pancagatra sebagai indikatornya.

\section{Metode}

Adapun jenis penelitian yang digunakan dalam penelitian ini adalah penelitian deskriptif kualitatif. Penelitian dengan metode ini bertujuan untuk melihat perilaku orang, peristiwa lapangan, serta kegiatan-kegiatan tertentu secara terperinci dan mendalam (Sanapiah, 1992). Metode pengumpulan data menggunakan teknik observasi, dokumentasi, studi pustaka dan penelusuran data online. Teknik analisis hasil pada penelitian ini menggunakan reduksi data, penyajian data dan penarikan kesimpulan.

Penelitian dilaksanakan di Kabupaten Jombang, Jawa Timur. Lokasi ini dipilih karena memiliki jumlah penderita gangguan jiwa yang terus meningkat setiap tahunnya. Kabupaten Jombang sendiri memiliki luas keseluruhan 1.159,50 $\mathrm{km}^{2}$. Secara administrasi Kabupaten Jombang terbagi menjadi 21 kecamatan, 302 desa dan 4 kelurahan serta 1.258 dusun. Jumlah penduduk Kabupaten Jombang tahun 2017 sebanyak 1.253.078 jiwa, terdiri 623.414 jiwa laki-laki dan 629.664 jiwa perempuan dengan 401.109 rumah tangga (KK) atau rata-rata 3,12 jiwa per rumah tangga dengan luas wilayah kabupaten Jombang $1.159 \mathrm{~km}^{2}$, maka tingkat kepadatan penduduk mencapai $1,081 / \mathrm{km}^{2}$. Tingkat kepadatan penduduk tertinggi di Kecamatan Jombang sebesar $4.059 \mathrm{jiwa} / \mathrm{km}^{2}$ sedangkan yang terendah adalah di Kecamatan Wonosalam sebesar 262 jiwa $/ \mathrm{km}^{2}$ (Pemerintah Kabupaten Jombang : 2017).

Pada aspek kesehatan, permasalahan kesehatan jiwa di Kabupaten Jombang perlu mendapatkan perhatian khusus. Jumlah penderita gangguan jiwa pada tahun 2015 hingga 2018 terus mengalami peningkatan, pada tahun 2015 sebanyak 1.086 jiwa masyarakat di Kabupaten Jombang menderita gangguan jiwa. Tahun 2016 jumlah penderita gangguan jiwa meningkat sebanyak 1.884 jiwa, tahun 2017 meningkat menjadi 2.343 jiwa dan hingga akhir 2018 jumlah penderita gangguan jiwa bertambah menjadi 2.701 jiwa. Penderita gangguan jiwa terbanyak berada pada wilayah kerja Puskesmas Perak dengan jumlah 187 penderita gangguan jiwa, keadaan tersebut berbanding terbalik dengan yang terjadi di wilayah kerja Puskesmas Bawangan yang memiliki 57 penderita gangguan jiwa namun terdapat 2 penderita gangguan jiwa yang dipasung. 


\section{Hasil dan Pembahasan}

\section{Hubungan Antara Gangguan Jiwa, Ketertiban Sosial dan Ketahanan Wilayah}

Gangguan jiwa yang terjadi dapat disebabkan oleh adanya tekanan pada pola perilaku dan pemikiran yang khas pada diri seseorang dan ketidakmampuannya untuk mengatasi tekanan tersebut. Apabila tidak diatasi dengan baik dapat menimbulkan gangguan pada ketertiban sosial di masyarakat, seperti munculnya tindakan kriminalitas atau pelanggaran lainnya yang menyebabkan timbulnya rasa tidak aman dan tidak nyaman dalam kehidupan sosial bermasyarakat. Penanganan permasalahan penderita gangguan jiwa di Kabupaten Jombang perlu mendapatkan perhatian serius dari pemerintah Kabupaten Jombang, koordinasi dan kerjasama yang baik antar SKPD (Satuan Kerja Perangkat Daerah) perlu ditingkatkan dan Peraturan Bupati sebagai payung hukum dalam pelaksanaan tugas penanganan penderita gangguan jiwa perlu dibuat. Hal tersebut dilakukan untuk mengantisipasi agar kejadian pada Agustus 2017 tidak terulang lagi, dimana pada saat itu terjadi tindakan pencurian sepeda motor yang sedang terparkir di pinggir sawah dengan pelaku seorang penderita gangguan jiwa dan 2 hari berikutnya terjadi pemukulan menggunakan balok kayu yang dilakukan oleh penderita gangguan jiwa kepada seorang warga yang sedang melintas, akibat kejadian tersebut seorang warga mengalami luka pada bagian pelipis sebelah kiri dan harus mendapatkan perawatan (Radar Jombang, 2017). Sedangkan pelaku kejahatan yang ternyata adalah penderita gangguan jiwa mendapatkan pengobatan / rehabilitasi di fasilitas kesehatan yang bekerjasama dengan pemerintah Kabupaten Jombang (Syafi'i, 2017). Kejadian tersebut menunjukkan bahwa fenomena gangguan jiwa memberikan dampak negatif terhadap gatra keamanan dan menimbulkan ketakutan atau teror di masyarakat.

Tindakan pelanggaran atau kriminal yang dilakukan oleh penderita gangguan jiwa tidak dapat dijatuhi hukuman, karena tindakan tersebut dilakukan di luar kesadaran pelaku. Namun untuk menentukan pelaku tindakan pelanggaran/kriminal tersebut benar menderita gangguan jiwa atau tidak harus didasari oleh bukti medis atau adanya saksi dan tanda-tanda gangguan jiwa secara fisik yang jelas. Perlu adanya peran aktif dari berbagai pihak yang terkait seperti dinas kesehatan, dinas sosial, aparatur keamanan dan tokoh masyarakat / tokoh agama setempat dalam memberikan bantuan pengobatan, rehabilitasi dan jaminan ketertiban sosial di masyarakat serta kehadiran pemerintah daerah dalam membuat kebijakan daerah. Terciptanya keteraturan sosial yang baik di masyarakat akan menciptakan suatu ketahanan wilayah yang kokoh dan tangguh baik dari aspek trigatra maupun pancagatra. Ketangguhan pancagatra terutama dalam gatra ekonomi diharapkan dapat meningkatkan kesejahteraan masyarakat dalam upaya pemenuhan kebutuhan hidupnya sehingga beban yang menjadi pemicu timbulnya gangguan dalam jiwa seseorang dapat diminimalisir.

Ketangguhan dalam gatra ekonomi terutama pada ketahanan ekonomi individu dan keluarga akan memberikan pengaruh positif bagi kemajuan ketahanan ekonomi wilayah dan perbaikan ketangguhan dalam gatra sosial dalam berinteraksi dan komunikasi di masyarakat agar kehadiran penderita gangguan jiwa dapat diterima dengan melibatkannya dalam kegiatan sosial, sehingga penderita gangguan jiwa terutama yang sudah sembuh tidak merasa rendah diri dan stigma negatif yang melekat pada penderita gangguan jiwa, seperti stigma bahwa penderita gangguan jiwa adalah seseorang yang mendapat guna-guna/kemasukan roh halus, tidak dapat disembuhkan serta 
harus dikucilkan dapat hilang dari lingkungan sosial. Penguatan gatra sosial akan memberikan dorongan pada penguatan gatra keamanan. Kondisi ketertiban sosial masyarakat akan menjadi lebih kondusif dan aman serta memberikan kenyamanan bagi masyarakat dalam melakukan aktivitas sehari-hari, sehingga teror dan berita hoax yang beredar di masyarakat dapat dihilangkan. Penguatan ketahanan pada gatra ekonomi, sosial, dan keamanan akan menumbuhkan rasa nasionalisme yang tangguh sehingga tercipta penguatan ketahanan diberbagai gatra sehingga diperoleh penguatan ketahanan wilayah Kabupaten Jombang.

\section{Penyakit Gangguan Jiwa dan Implikasinya terhadap Ketahanan Wilayah}

Munculnya fenomena gangguan jiwa, berimplikasi pada gatra ekonomi, gatra sosial dan gatra keamanan. Penyakit gangguan jiwa yang diderita memenjarakan kesempatan untuk dapat berkreasi dan berkarya, mereka pun harus kehilangan kemampuan dalam berpikir dan melakukan aktivitas secara mandiri, keadaan tersebut membuatnya tidak lagi dapat bekerja secara produktif sehingga untuk dapat memenuhi kebutuhan dan kewajibannya sehari - hari cenderung menggantungkan hidupnya pada orang lain. Ketidakmampuan seseorang dalam mengelola tingkat tekanan pada kebutuhan ekonomi mendorong untuk melakukan tindakan kriminal dan kejahatan. Jika dihitung dengan menggunakan Upah Minimum Regional (UMR) Kabupaten Jombang tahun 2018 sebesar Rp. 2.264.136,- dikalikan dengan jumlah keseluruhan penderita gangguan jiwa yang terdata di Dinas Kesehatan Kabupaten Jombang pada tahun 2018 sebanyak 2.701 jiwa, maka setiap bulannya terjadi kerugian potensi ekonomi sebesar Rp. 6.115.431.336,- atau Rp. 73.385.176.032,setiap tahunnya. Belum lagi jika penderita gangguan jiwa harus didampingi oleh anggota keluarga, secara tidak langsung aktivitas anggota keluarga yang menjadi pendamping mengalami hambatan, diasumsikan bahwa hambatan tersebut sebesar 50\% dari jumlah kerugian potensi ekonomi per bulannya maka sebesar Rp.3.057.715.668,- setiap bulan harus hilang atau sebesar Rp.36.692.588.016,- setiap tahunnya.

Sebagai unit terdekat dengan penderita, keluarga tentu saja turut menerima dampak negatif dari hilangnya kesadaran dan kemampuan yang dimiliki oleh orang dengan gangguan jiwa. Pendapatan perekonomian keluarga menjadi menurun sedangkan beban ekonomi keluarga menjadi meningkat. Keluarga juga memiliki beban tambahan untuk menjaga dan merawatnya sehingga aktivitas dan waktu bekerja yang dimiliki menjadi terbagi, sebagian besar keluarga penderita gangguan jiwa tidak memiliki penghasilan tetap, mereka menggantungkan hidupnya dari hasil buruh tani yang bekerja pada saat musim panen, buruh pabrik, buruh kasar dan serabutan yang besarnya pendapatan tidak menentu (sektor informal).

Sebagai upaya meningkatkan kesejahteraan masyarakat dan mendorong perekonomian agar lebih maju, pemerintah Kabupaten Jombang memberikan bantuan kepada usaha mikro kecil menengah (UMKM) dengan harapan dapat memperluas lapangan pekerjaan, memberikan pelayanan ekonomi secara luas kepada masyarakat, berperan dalam proses pemerataan dan peningkatan pendapatan masyarakat, mendorong pertumbuhan ekonomi dan mewujudkan stabilitas nasional. Fenomena gangguan jiwa juga memberikan dampak negatif terhadap gatra sosial, terjadinya pengucilan kepada penderita gangguan jiwa dalam pergaulan di masyarakat menyebabkan munculnya isolasi sosial, pemasungan, stigma dan labelling gila. 
Penderita gangguan jiwa mengalami penurunan kepercayaan diri yang mengakibatkan mereka menjadi menjauh dan cenderung menarik diri dari lingkungan sosial. Seseorang yang hidup dalam keadaan normal cenderung akan bergaul dan memilih teman yang memiliki kesamaan sudut pandang, mereka akan senang bertukar pikiran untuk merencanakan pendidikan selanjutnya dan berkarya menunjukkan ide kreatifitas yang dimiliki sebagai upaya dalam pemenuhan kebutuhan pribadinya. Isolasi sosial yang dilakukan oleh penderita gangguan jiwa menjadikan mereka hidup secara individualisme bahkan tidak jarang mereka melakukan tindakan kekerasan dan melukai diri sendiri yang berujung pada terjadinya tindakan pemasungan oleh keluarga, sebanyak 14 penderita gangguan jiwa di Kabupaten Jombang masih mengalami pemasungan (Dinkes Kabupaten Jombang, 2020). Tindakan pemasungan terjadi karena : (1) adanya kegiatan atau aktivitas membahayakan yang dilakukan oleh penderita gangguan jiwa, baik membahayakan bagi diri penderita gangguan jiwa sendiri maupun orang lain, (2) ketidakmampuan keluarga dalam memberikan perhatian dan dukungan perawatan kepada penderita gangguan jiwa, (3) minimnya pengetahuan keluarga dan berkembanganya pemahaman yang diyakini oleh masyarakat sekitar terhadap penanganan penderita gangguan jiwa.

Adanya stigma bahwa penyakit gangguan jiwa tidak dapat disembuhkan menyulitkan penderita gangguan jiwa untuk memperoleh kesembuhan, bahkan penderita gangguan jiwa yang telah sembuh juga tetap dikatakan sebagai mantan orang gila. Kata "gila" seolah menjadi labelling yang tidak dapat dihilangkan. Stigma dan labelling gila yang selama ini melekat pada mantan penderita gangguan jiwa harus dihilangkan agar tidak menjadi beban moral dan pemicu terjadinya kekambuhan. Masyarakat harus menerima dan memberikan kepercayaan kepada mantan penderita gangguan jiwa untuk melanjutkan kehidupannya dengan lebih baik. Fenomena gangguan jiwa juga memberikan ancaman dan gangguan keamanan, seperti tindakan pengrusakan, kriminal dan keresahan di masyarakat yang disebabkan oleh penderita gangguan jiwa menjadi teror dan ketakutan tersendiri bagi masyarakat. Ketakutan akan menjadi korban kekerasan dan kriminal penderita gangguan jiwa menimbulkan beredarnya berita hoax yang sulit dicegah penyebarannya. Sepanjang tahun 2018 tercatat ada 5 kejadian penganiayaan yang dilakukan oleh orang dengan gangguan jiwa terhadap tokoh agama di Jawa Timur (Medistiara, 2018).

Sebagai respon atas permasalahan tersebut Dinas Sosial bekerjasama dengan Kepolisian, Satpol PP dan TNI melakukan razia penderita gangguan jiwa di jalan - jalan Kabupaten Jombang. Razia dimaksudkan untuk mencegah adanya tindakan kriminal yang dilakukan oleh orang dengan gangguan jiwa atau memanfaatkan orang dengan gangguan jiwa untuk menciptakan kekacauan dan keresahan di masyarakat. Kegiatan tersebut mendapat apresiasi dan dukungan dari masyarakat. Adanya razia yang dilakukan oleh Polres Jombang dapat meredam berita tidak benar yang beredar sehingga menimbulkan rasa aman di lingkungan sosial. Keamanan yang terjaga dan hadirnya rasa nyaman akan meningkatkan ketertiban sosial di masyarakat sehingga suasana yang lebih kondusif dapat tercipta dan memberikan kepercayaan bagi investor dan wisatawan dalam menggerakkan roda perekonomian dan meningkatkan kesejahteraan.

Ketidaksatabilan kondisi keamanan yang disebabkan oleh adanya terror dan berita hoax yang beredar memberikan dampak negatif bagi ketahanan keamanan di wilayah Kabupaten Jombang, kekhawatiran dan ketakutan tersebut bahkan juga memberikan dampak terhadap 
penurunan iklim investasi yang menyebabkan rendahnya daya saing perekonomian Kabupaten Jombang dengan wilayah lain disekitarnya. Tingginya jumlah penderita gangguan jiwa tentunya tidak dapat dinyatakan sebagai kegagalan individu semata namun juga kegagalan masyarakat dan lingkungan sosial, seperti kegagalan dalam menciptakan komunikasi sosial yang baik di lingkungan masyarakat dan keluarga. Hubungan keluarga yang buruk memberikan dampak yang buruk pula terhadap pola asuh di dalam keluarga, seperti pola asuh otoriter, pola asuh memanjakan, tidak terciptanya hubungan baik antara ayah dan ibu / orang tua terhadap anak dan terjadinya persaingan antar keluarga yang dapat memicu hadirnya konflik dalam keluarga tersebut sehingga lambat laun akan mengakibatkan munculnya stres, depresi hingga berujung pada gangguan kejiwaan terhadap anggota keluarga, semua hal tersebut berkaitan dengan faktor sumber daya manusia yang terdapat di Kabupaten Jombang.

Ketahanan wilayah tidak dapat tercipta dengan sendirinya, diperlukan perpaduan dan penguatan dengan ketahanan lainnya sehingga membentuk suatu kekuatan ketahanan baru dengan ruang lingkup yang lebih luas yaitu kewilayahan. Ketahanan wilayah dapat dipengaruhi oleh perkembangan fenomena sosial di masyarakat dan upayanya dalam mengatasi permasalahan yang ada, semakin cepat kemampuan suatu daerah dalam mengatasi permasalahan maka semakin kuat juga ketahanan wilayahnya, begitu pun sebaliknya. Besarnya potensi ekonomi yang hilang karena penyakit gangguan jiwa yang diderita maka penanganan dalam penyembuhan penderita gangguan jiwa tidak hanya mencakup pada penyembuhan penyakit secara fisik dari penderita saja tetapi juga harus dapat menyembuhkan kesulitan ekonomi yang diderita, salah satu cara yang dapat dilakukan adalah memberikan pelatihan keterampilan dan kemampuan diri sesuai dengan minat bakat yang dimiliki melalui komunitas posyandu jiwa.

Penderita gangguan jiwa yang tergabung dalam komunitas Posyandu Jiwa Pelita Harapan di Desa Bongkot diberikan berbagai pelatihan keterampilan dengan harapan agar penderita gangguan jiwa memiliki rasa percaya diri yang mendorong mereka untuk dapat hidup mandiri dan memenuhi kebutuhan pribadinya sendiri sehingga tidak menjadi beban keluarga. Penderita gangguan jiwa yang telah dapat berkarya dijadikan ambasador dalam program penanganan penderita gangguan jiwa sehingga masyarakat menjadi sadar dan percaya sepenuhnya bahwa penderita gangguan jiwa dapat disembuhkan dan bukan merupakan penyakit yang disebabkan oleh guna guna atau hal gaib lainnya. Upaya lain yang dilakukan adalah melibatkan keluarga, masyarakat dan tokoh setempat dalam menciptakan keamanan dan keharmonisan kehidupan bermasyarakat dengan cara menghidupkan forum komunikasi umat beragama. Melalui forum komunikasi umat beragama yang diikuti oleh masyarakat dan tokoh memberikan berpengaruh terhadap derajat kesehatan karena masyarakat Kabupaten Jombang masih menganut budaya model, perkataan dan perilaku tokoh agama sangat dipercaya dan dipatuhi. Oleh karenanya dalam pelaksanaan penyuluhan kesehatan jiwa menggunakan media pertemuan keagamaan, seperti kegiatan pengajian.

\section{Kesimpulan}

Berdasarkan bahasan diatas, penelitian ini menghasilkan kesimpulan bahwa keberadaan para penderita gangguan jiwa di Kabupaten Jombang berdampak pada aspek ketahanan wilayah tersebut, baik secara ekonomi, sosial dan keamanan. Pada gatra ekonomi telah terjadi penurunan 
kemampuan ekonomi individu yang berdampak pada pelemahan kemampuan ekonomi keluarga dan wilayah. Kemampuan ekonomi wilayah akan meningkat apabila didukung oleh penguatan kemampuan ekonomi keluarga sedangkan penguatan kemampuan ekonomi keluarga bergantung pada penguatan ketahanan individu yang meliputi keterampilan dan kemampuan ekonomi. Selain itu, dalam gatra sosial terjadinya isolasi sosial serta pemasungan akibat adanya stigma dan labelling gila kepada penderita gangguan jiwa. Stigma dan labelling gila yang diberikan kepada penderita gangguan jiwa hanya akan memperburuk kondisi kejiwaan penderita sehingga menyebabkan terjadinya isolasi sosial dan pemasungan terhadap penderita gangguan jiwa. Stigma dan labelling gila harus dihilangkan dan diganti dengan pemberian ruang sosial bagi keluarga dan penderita gangguan jiwa. Kemudian pada gatra keamanan, fenomena gangguan jiwa menimbulkan teror yang disebabkan karena adanya tindakan pengrusakan, kriminal dan keresahan di masyarakat hingga beredarnya berita hoax yang meresahkan.

Melalui penelitian ini, penulis menyarankan agar Pemerintah Kabupaten Jombang untuk menyediakan posyandu jiwa di setiap puskesmas yang endemik gangguan jiwa, pelatihan keterampilan perawatan jiwa bagi tenaga kesehatan secara bertahap dan berjenjang serta pemenuhan ketersediaan obat di setiap fasilitas kesehatan untuk penderita gangguan jiwa. Keluarga sebagai unit terkecil dan terdekat harus memiliki kepedulian untuk merawat anggota keluarganya yang menderita gangguan jiwa sesuai dengan kemampuannya. Keluarga juga harus memberikan dorongan dan motivasi bagi penderita gangguan jiwa untuk mendapatkan pengobatan yang benar di fasilitas kesehatan serta menerapkannya dalam lingkungan rumah. Lingkungan menjadi kawah candradimuka bagi penderita gangguan jiwa yang telah sembuh, sehingga menjadi sangat penting untuk mendukung dan memberikan ruang sosial bagi mantan penderita gangguan jiwa. Kebiasaan salah yang berkembang di masyarakat harus dihilangkan, seperti merubah kebiasaan buang air di sungai dengan menyediakan sarana jamban sehat di rumah dan tidak menempatkan kandang hewan berdekatan dengan tempat tinggal, penempatan hewan ternak yang berdekatan dengan tempat tinggal sangat berisiko terhadap penularan penyakit dari hewan ternak kepada manusia. Masyarakat harus lebih peduli terhadap kebersihan dan kenyamanan lingkungan.

\section{Referensi}

Andina, E. (2013). Pelindungan bagi Kelompok Berisiko Gangguan Jiwa. Jurnal Aspirasi, 4(2), 143154. https://doi.org/10.22212/aspirasi.v4i2.497

Amal, I. (1995). Sumbangan Imu Sosial Terbadap Konsepsi Ketahanan Nasional. Universitas Gajah Mada Press.

Dinkes Kabupaten Jombang. (2020). Profil Kesehatan Kabupaten Jombang 2019. https://dinkes.jombangkab.go.id/assets/files/Profil Kesehatan/2019/Profil Kesehatan Kab Jombang 2019.pdf

Haas, K. (1997). Abnormal Psychology (1st ed.). Van Nostrand.

Kemenkes RI. (2016). Peran Keluarga Dukung Kesehatan Jiwa Masyarakat. Sehat Negeriku. https://sehatnegeriku.kemkes.go.id/baca/rilis-media/20161006/4318188/peran-keluargadukung-kesehatan-jiwa-masyarakat/

Kemenkes RI. (2018). Hasil Riset Kesehatan Dasar Tahun 2018. Kementrian Kesebatan RI, 53(9), 
Copyright (C) 2021, Febiadi Faisal Hakim

This is an open access article under the CC-BY-SA

license
ISSN 2088-8090 (Print) ISSN 2597-6648 (Online)

Sospol: Jurnal Sosial Politik Vol 7 No 2 (2021), pp.202-211

1689-1699.

Lubis, N., Krisnani, H., \& Fedryansyah, M. (2014). Pemahaman Masyarakat Mengenai Gangguan Jiwa dan Keterbelakangan Mental. Share: Social Work Journal, 4(2). https://doi.org/10.24198/share.v4i2.13073

Medistiara, Y. (2018). Penganiaya Ulama Diduga Gangguan Jiwa, GP Ansor: Harus Dibuktikan. Detik News. https://news.detik.com/berita/d-3848849/penganiaya-ulama-diduga-gangguanjiwa-gp-ansor-harus-dibuktikan.

Pemerintah Kabupaten Jombang, 2017, Peta Kabupaten Jombang, http://www.jombangkab.go.id/ (diakses tanggal 5 April 2018).

Radar Jombang. (2017). Sakit Jiwa Curi Motor. Radar Jombang. https://radarjombang.jawapos.com/read/2020/09/07/212600/curi-motor-tetangga-

sendiri-residivis-asal-megaluh-dibekuk-polisi

Sanapiah, F. (1992). Format-Format Penelitian Sosial. Rajawali Press.

Slamet, Suprapti; Markam, S. (2007). Pengantar Psikologi Klinis. UI Press.

Sugiyono. (2008). Metode Penelitian Kuantitatif Kualitatif dan R\&DD. Alfabeta.

Syafi'i, M. (2017). Orang Gila Berulah, Warga Kepatiban Jombang Geger. Faktualnews.Co. https:// faktualnews.co/2017/08/07/orang-gila-berulah-warga-kepatihan-jombanggeger/30323/

Videbeck, S. L. (2008). Buku Ajar Keperawatan Jiwa. EGC. 